\title{
A IMPORTÂNCIA DA PRÁTICA AVALIATIVA NO PROCESSO DE ENSINO - APRENDIZAGEM NA EDUCAÇÃO INFANTIL
}

\author{
Tiago Pelegrin Elias ${ }^{1}$
}

RESUMO: O objetivo deste artigo é trazer uma reflexão sobre a importância da Avaliação como prática transformadora no processo de ensino aprendizagem na Educação Infantil. Os estudos da prática avaliativa no contexto escolar são de suma importância para que o educador se certifique da aprendizagem, sendo promovida com qualidade e equidade. $\mathrm{Na}$ Educação infantil, principalmente, a escola deve ser um espaço democrático e libertador, espaço esse em que a criança seja acolhida e que seu direito de aprendizagem seja garantido por meio de práticas pedagógicas significativas, conectadas à avaliação como principal ferramenta para o desenvolvimento integral dos sujeitos.

Palavras-chave: Avaliação. Educação infantil. Ensino aprendizagem.

ABSTRACT: The aim of this article is to cause a reflection about the importance of evaluation as a transforming practice on teaching-learning process on the Children Education. The studies of Evaluation practice on school context and has its relevance for the educator make sure that learning is promoted with quality and equity. In children's education, especially, the school should be a democratic and liberating space, space that the children are welcome and that their right to learning is guaranteed by a significant pedagogical practice, with the assessment as the main tool for the full development of children.

Keywords: Evaluation. Children Education. Teaching-learning.

\section{INTRODUÇÃO}

O processo avaliativo configura-se em algo intrigante e envolvente que há muito tempo desperta interesse dos pesquisadores da área da educação. Os estudos sobre as teorias avaliativas são de suma importância para aprendizagem dos alunos. Aprender é uma capacidade do ser humano e ensinar é proporcionar o desenvolvimento desta capacidade intelectual e psicológica.

Avaliar é, principalmente, fornecer aos alunos situações planejadas de modo que possam viver as experiências necessárias para produzir neles as transformações desejadas.

\footnotetext{
${ }^{\text {I }}$ Graduado em Letras pela Universidade Braz Cubas. Pós-graduado (lato sensu) em Educação Infantil pela Universidade Cruzeiro do Sul. Pós-graduado (lato sensu) em Gestão Escolar. Professor de Inglês na Educação de Jovens e Adultos pela Prefeitura Municipal de Santo André e Professor de inglês no Ensino Fundamental I de Prefeitura Municipal de Osasco.
} 
Para isso, o educador precisa de ferramentas que subsidiem o trabalho pedagógico. A avaliação é uma dessas ferramentas, senão a mais importante, pois através dela o professor consegue direcionar o processo ensino-aprendizagem para atingir os objetivos propostos.

Em concepções tradicionalistas de avaliação, o caráter classificatório, seletivo e excludente apresenta muitos prejuízos ao cenário escolar, pois não corrobora com práticas que promovem a autonomia no desenvolvimento de competências e habilidades.

A avaliação é uma poderosa aliada do processo de ensino aprendizagem e deve ser feita intencionalmente e diariamente. $\mathrm{Na}$ Educação infantil, os professores não devem avaliar apenas para cumprir exigências do sistema educacional em conceituar o aprendiz, mas avaliar para promover uma aprendizagem significativa e que visa à formação integral dos sujeitos.

Considerando a avaliação escolar como uma prática presente no cotidiano dos alunos, surge então a hipótese de que a avaliação é de suma importância para uma prática que visa à qualidade da aprendizagem na Educação Infantil.

\section{OBJETIVO}

Apresentar algumas teorias de avaliação e sua perspectiva na Educação Infantil, e identificar o quanto a avaliação impacta na aprendizagem das crianças como uma aliada do processo de ensino aprendizagem.

\section{OBJETIVOS ESPECÍFICOS}

Analisar as principais teorias sobre avaliação infantil; enfatizar a importância de práticas avaliativas à luz dos fundamentos teóricos para a aprendizagem significativa; mostrar como o trabalho avaliativo deve ser realizado na etapa da Educação Infantil.

\section{JUSTIFICATIVA}

A importância dos estudos sobre "Avaliação" reflete na aprendizagem dos alunos de forma significativa. Pois a avaliação faz parte da vida de qualquer cidadão, seja na escola ou também fora dela. A prática avaliativa em caráter diagnóstico, mediador e qualitativo contribui para uma pedagogia que visa a formação integral dos sujeitos. 
No âmbito escolar, a avaliação ainda é vista como uma tarefa punitiva e tende a assustar os alunos. Portanto, na educação infantil, principalmente, faz-se necessário uma prática avaliativa diária, transformadora e que ressignifique e considere todo o processo de aprendizagem como parte integrante da vida das crianças.

\section{METODOLOGIA}

Este trabalho foi realizado por intermédio de pesquisa bibliográfica. Ou seja, desenvolvido e fundamentado com base em livros e artigos científicos sobre a temática em questão.

A pesquisa bibliográfica pode ser realizada independentemente ou pode constituir parte de uma pesquisa descritiva ou experimental. Segundo Cervo, Bervian e da Silva (2007, p.6I), a pesquisa bibliográfica adota o procedimento básico para os estudos monográficos, pelos quais se busca o domínio do estado da arte sobre determinado tema.

As teorias de Hoffmann (2007 e 2009), Vasconcellos (2013), Zabala (1998) e Demo (20I0) são de suma importância para que o educador compreenda o processo de avaliação e suas peculiaridades. Os autores em questão, entre outros que são abordados neste artigo, entendem a avaliação como um processo que promove a aprendizagem, sobretudo, indissociável da prática docente.

\section{CONCEPÇÕES DE AVALIAÇÃO}

Para Zaballa (1998), a avaliação é considerada como um instrumento sancionador e que de alguma forma qualifica. Sendo o sujeito da avaliação somente o aluno, e o objeto da avaliação são as aprendizagens realizadas segundo objetivos mínimos para todos. Por outro lado, o sujeito da avaliação não se centra apenas no aluno, como também na equipe que intervém no processo (ZABALLA, 1998, p.198).

De acordo com Hoffmann (2009), o princípio da avaliação se fundamenta na visão dialética do conhecimento e implica a questão da historicidade, ou seja, o conhecimento humano visa sempre ao futuro, à evolução, à superação. A avaliação está predominantemente a serviço da ação, colocando o conhecimento obtido, pela observação ou investigação, a fim de garantir a melhoria da situação avaliada (HOFFMANN, 2009, p.17). 
A autora defende uma prática avaliativa que promove a aprendizagem. Para isso, o educador, em sua ação avaliativa, não deve se fundamentar na verificação de registro de dados do desempenho escolar, mas na observação permanente das manifestações de aprendizagem para proceder a uma ação educativa otimista dos percursos individuais.

Avaliar para promover, segundo Hoffmann (2009) significa:

compreender a finalidade dessa prática a serviço da aprendizagem, da melhoria da ação pedagógica, visando à promoção moral e intelectual dos alunos. $\mathrm{O}$ professor assume o papel de investigador, de esclarecedor, de organizador de experiências significativas de aprendizagem. Seu compromisso é o de agir refletidamente, criando e recriando alternativas pedagógicas adequadas a partir da melhor observação e conhecimento de cada um dos alunos, sem perder a observação e promovendo sempre ações interativas". (Hoffmann, 2009).

Analisando a perspectiva de Hoffmann, avaliar é dar voz aos alunos para que a investigação possa ser realizada a fim de observar o que os alunos aprendem nas situações de aprendizagens propostas pelo professor. As ações interativas devem ser planejadas com intencionalidade.

Para Demo (2010), o processo de avaliação não diz respeito apenas ao ensino e nem pode ser reduzido a técnicas somente. Diz respeito à reflexão permanente sobre a atividade humana. A avaliação constitui um processo intencional, auxiliado por diversas ciências, se aplicando a qualquer prática (DEMO, 2010, p.9). O autor em questão ressalta que o processo de avaliação não pode estar restrito apenas nas estratégias de avaliação, mas durante todo o processo, na ação e reflexão.

Segundo Vasconcellos (2013), avaliar é localizar necessidades e se comprometer com sua superação. Em qualquer situação de vida, a questão básica é de fato está sendo avaliado. No sentido escolar, avaliação só deve acontecer para haver intervenção no processo de ensino aprendizagem. $\mathrm{O}$ autor salienta que:

\footnotetext{
Pode haver mudança no conteúdo e na forma de avaliar, pode haver mudança na metodologia de trabalho em sala de aula e até na estrutura da escola, e, no entanto, não se tocar no que é decisivo: intervir na realidade a fim de transformar. Se não houver um re-enfoque da própria intencionalidade da avaliação, de pouco adiantará” (Vasconcellos, 2013, p.44).
}

A principal característica da avaliação defendida por Vasconcellos (2013) é a intencionalidade, que assume o direcionamento dessa prática e que possibilita a reflexão por parte do docente. A intenção é movida por uma questão crucial: Avaliar para quê? Para localizar a necessidade do aluno e para atender à superação. Quando a dificuldade é localizada, o dever do professor é de se comprometer com a busca de estratégias que visam 
à superação das barreiras encontradas. Para Vasconcellos (2013, p. 42), "Uma outra acepção possível para intenção é a de fim que se propõe atingir”.

Zaballa (1998), afirma que:

A intencionalidade é um dos aspectos mais difíceis de serem trabalhados e até explicitados, quer por sua importância ou, principalmente, por sua sutileza: é um campo onde facilmente corre livre o discurso do novo senso comum pedagógico e pode confundir muito os educadores. A concretização de uma nova intencionalidade é, a nosso ver, o maior desafio contemporâneo da avaliação da aprendizagem" (ZABALLA, 1998, p.45).

Analisando as condições para a mudança da intencionalidade da avaliação, encontram-se muitos obstáculos. Um dos maiores, como aponta Zaballa (1998), é a tradição avaliativa já existente. Conhecida e aplicada em alguns sistemas de ensino como “Avaliação classificatória”, ou seja, a avaliação tradicional. Tal prática dissemina a cultura da repetência e tende a contribuir para os elevadíssimos índices de reprovação e evasão escolar, caracterizado por alguns autores como "fracasso escolar".

Para Marchesi \& Pérez (2004), são três as questões que norteiam o fracasso escolar. A primeira delas diz que o aluno "fracassado" é aquele que não progrediu praticamente nada durante seus anos escolares, nem no âmbito de seus conhecimentos, nem do seu desenvolvimento pessoal e social.

A segunda questão diz que o problema central reside no fato de que o termo qualifica uma imagem negativa do aluno, afetando sua autoestima e sua confiança.

Por último a terceira questão centraliza no aluno o problema do fracasso e distancia a responsabilidade de outros agentes e instituições, como as condições sociais, a família, o sistema educacional ou a própria escola (MARCHESI \& PÉREZ, 2004, p.17)

A compreensão do que se entende por fracasso escolar, muitas vezes, é reduzida a ideia de avaliação. Nesse sentido, o aluno fracassa quando é incapaz de reproduzir o que "aprendeu” ou "construiu" ao longo do processo. Os professores adotam, ainda hoje, estratégias de avaliação que não são eficazes, sendo elaboradas para que o aluno reproduza algo que deveria ter absorvido, de forma totalmente descontextualiza.

Devido à falta de formação, os docentes avaliam tradicionalmente e classificam seus alunos como bons ou ruins.

Para Hoffmann (2007), o sistema de avaliação classificatória é vago porque não é capaz de apontar as falhas no processo de aprendizado dos alunos e nas práticas de ensino 
do professor. Se garantisse a boa qualidade da educação, as estatísticas não seriam tão negativas em relação à realidade das escolas brasileiras.

Ao estudante cabe exclusivamente responder questões com respostas sempre sugeridas pelo professor e pelo livro didático. Nesse caso, agradar ao educador é a meta principal. Os alunos que alcançam boas notas, em muitos casos, aprendem apenas para passar no exame, adotando práticas como memorização, obediência e passividade (HOFFMANN, 2007, p.22).

Tradicionalmente, o ato de avaliar apresentava caráter seletivo, classificatório e excludente, uma vez que era vista apenas como uma forma de classificar e promover o aluno de uma série para outra, de um grau a outro.

Para Haydt (2008), nos dias de hoje, as concepções educacionais exigem que a avaliação seja fator indissociável do processo ensino-aprendizado e para tanto têm que acompanhar seus fundamentos e princípios. A avaliação hoje assume novas funções, de dimensões orientadoras, pois propõem diagnosticar e verificar em que medida os objetivos propostos estão sendo ou não atingidos (HAYDT, 20o8, p.I4).

Portanto, tratando-se de Avaliação, na perspectiva dos autores em estudo, vale ressaltar algumas distinções que são fundamentais para uma prática transformadora na aprendizagem dos alunos.

Para Fernandes \& Freitas (2007), a avaliação é apresentada como uma das atividades do processo pedagógico, necessariamente inserida no Projeto Político Pedagógico da instituição de ensino, e não deve, portanto, ser considerada descontextualizada (FERNANDES \& FREITAS, 2007, p.II)

De certa forma, ainda é bastante comum as pessoas entenderem que não se pode avaliar sem que os estudantes recebam uma nota pela sua produção. Avaliar, para o senso comum, aparece como sinônimo de medida, de atribuição de um valor em forma de nota ou conceito. Porém, os educadores têm o compromisso de ir além do senso comum, e não confundir avaliar com medir.

A avaliação é uma atividade orientada para o futuro. Avalia-se para tentar manter ou melhorar nossa atuação futura. Essa é a base da distinção entre medir e avaliar. Medir refere-se ao presente e ao passado e visa obter informações a respeito do progresso efetuado pelos estudantes. Avaliar refere-se à reflexão sobre as informações obtidas com vistas a planejar o futuro. Portanto, medir não é avaliar, ainda que o medir faça parte do processo de avaliação.” (Fernandes e Freitas, 2007). 
Sendo assim, a avaliação é parte do processo educacional e não deve assumir um caráter classificatório a fim de comprometer a autoestima dos alunos, e tampouco de se consolidar como excludente e punitiva.

A avaliação deve acontecer com o intuito de promover a aprendizagem significativa, de diagnosticar possíveis dificuldades, bem como a reorientação da prática pedagógica. Avaliar significa observar todo o processo de ensino aprendizagem, com o intuito reflexivo sobre as informações obtidas para o planejamento do futuro, no sentido de acompanhamento do desenvolvimento do estudante.

\section{A EDUCAÇÃO INFANTIL}

A importância da avaliação no processo de ensino e aprendizagem, também na Educação infantil, é indiscutível, pois subsidia os alunos nas possíveis dificuldades e os professores na reflexão de seu trabalho.

De acordo com a BNCC - Base Nacional Curricular Comum (2016), a Educação Infantil, primeira etapa da Educação Básica, cumpre o seu papel ao proporcionar às crianças diferentes experiências de interações, possibilitando diversas formas de agrupamento (grupos de mesma idade e de diferentes idades), formados com base em critérios pedagógicos.

Caracteriza-se por ser ofertada em tempo integral ou parcial, tendo parte de sua oferta, a creche, para crianças de o a 3 anos, com matrícula optativa, e parte na pré-escola, crianças de 4 e 5 anos, com a obrigatoriedade de matrícula a partir da Emenda Constitucional no. 59/2009 (BNCC, 2007, p.53).

A Educação Infantil não se utiliza de processos avaliativos para a promoção ou retenção das crianças. Se não é para promover a séries posteriores, deve-se então discutir qual o objetivo da avaliação nesse nível de ensino.

Pode-se analisar para quê e a quem serve avaliarmos as crianças de zero a cinco anos. Essas características do atendimento à Educação Infantil, centrais no modo como a etapa se configura, são derivadas das peculiaridades das crianças. Ou seja, a avaliação deve ser realizada minuciosamente a fim de garantir as crianças o que lhe é de direito.

Citadas na BNCC (2016), as Diretrizes Curriculares Nacionais da Educação Infantil - DCNEI (Parecer CNE/CEB nº 20/o9) tratam de seis direitos de aprendizagem 
que devem ser garantidos na Educação Infantil, pelas quais bebês e crianças aprendem e constroem significações sobre si, os outros e o mundo social e natural; as exigências fundamentais da vida contemporânea e a inserção da Educação Infantil no sistema educacional. São os direitos:

CONVIVER democraticamente com outras crianças e adultos, com eles se relacionar e partilhar distintas situações, utilizando diferentes linguagens, ampliando o conhecimento de si e do outro, o respeito em relação à natureza, à cultura $e$ às diferenças entre as pessoas.

BRINCAR cotidianamente de diversas formas, em diferentes espaços e tempos, com diferentes parceiros, adultos e crianças, ampliando e diversificando as culturas infantis, seus conhecimentos, sua imaginação, sua criatividade, suas experiências emocionais, corporais, sensoriais, expressivas, cognitivas, sociais e relacionais.

PARTICIPAR ativamente, junto aos adultos e outras crianças, tanto do planejamento da gestão da escola, como da realização das atividades da vida cotidiana: da escolha das brincadeiras, dos materiais e dos ambientes, desenvolvendo linguagens e elaborando conhecimentos, decidindo e se posicionando.

EXPLORAR movimentos, gestos, sons, palavras, emoções, transformações, relacionamentos, histórias, objetos, elementos da natureza, no contexto urbano e do campo, espaços e tempos da instituição, interagindo com diferentes grupos e ampliando seus saberes, linguagens e conhecimentos.

EXPRESSAR, como sujeito criativo e sensível, com diferentes linguagens, sensações corporais, necessidades, opiniões, sentimentos e desejos, pedidos de ajuda, narrativas, registros de conhecimentos elaborados a partir de diferentes experiências, envolvendo tanto a produção de linguagens quanto a fruição das artes em todas as suas manifestações.

CONHECER-SE e construir sua identidade pessoal, social e cultural, constituindo uma imagem positiva de si e de seus grupos de pertencimento, nas diversas experiências de cuidados, interações e brincadeiras vivenciadas na instituição de Educação Infantil” (BNCC, 2016, p.6I)

Para o alcance da formação integral dos sujeitos a qualidade do trabalho pedagógico é crucial e deve ser priorizada. Os direitos citados devem ser garantidos, sendo de total responsabilidade do professor e das instituições de ensino.

Os espaços educativos devem ser organizados para favorecer o desenvolvimento da criança com diferentes maneiras de interação e participação. O processo avaliativo está presente desde o momento da organização desses espaços e consiste em observar cada etapa.

Oliveira (2002, p.255) enfatiza a respeito da avaliação infantil quando diz que "[...] implica detectar mudanças em competências das crianças que possam ser atribuídas tanto ao trabalho na creche e pré-escola quanto à articulação dessas instituições com o cotidiano 
escolar [...]”. A autora traz uma reflexão relevante para justificar o quanto a Educação infantil deve ser um campo de investigação.

Para que de fato a investigação realizada pelo docente contribua para formação das crianças, é imprescindível que as anotações, registros e relatórios sejam feitos com o intuito de avaliar cada etapa e fornecer meios para ação, reflexão e mudança.

Dahlberg, Moss \& Pence (2003) apresentam uma concepção divergente da observação, que é a documentação pedagógica. Os autores apontam como os enfoques se diferenciam: [...] a "observação da criança" diz respeito principalmente à avaliação do fato de ela estar adaptada a um conjunto de padrões. A "documentação pedagógica” diz respeito principalmente à tentativa de enxergar e entender o que está acontecendo no trabalho pedagógico e o que a criança é capaz de fazer sem qualquer estrutura predeterminada de expectativas e normas (DAHLBER, MOSS \& PENCE, p. 192).

O docente necessita de clareza sobre o processo do seu trabalho pedagógico e a avaliação torna-se uma aliada para que esse processo seja eficaz e contribua para o desenvolvimento infantil.

O Referencial Curricular Nacional para a Educação Infantil (Brasil, 1998), traz uma visão de avaliação que corrobora com a perspectiva dos autores em questão, ou seja, um conjunto de ações que auxiliam o professor a refletir sobre as condições de aprendizagens oferecidas e ajustar a sua prática às necessidades colocadas pela criança.

Não há a menor vinculação com a questão classificatória, punitiva ou ainda promocional, que erroneamente são vinculadas à avaliação. $O$ documento explicita a questão avaliativa como elemento indissociável do processo educativo que possibilita ao professor definir critérios para planejar as atividades e criar situações que gerem avanços na aprendizagem das crianças. Tem como função acompanhar, orientar, regular e redirecionar esse processo como um todo (Brasil, 1998, v. I, p.59).

Avaliar, na Educação Infantil, assume sua função fundamental de acompanhar as crianças em suas aprendizagens. Para que esse processo aconteça, o educador deve ter clareza nas suas intenções e acreditar na sua prática avaliativa como forma de assegurar a aprendizagem de seus alunos em seus diferentes níveis. Se a intenção é a aprendizagem do aluno, o processo avaliativo deve considerar a turma de alunos e a especificidade de cada 
um. A avaliação deve ser contínua e formativa, um ato de amor, como afirma Luckesi (2002, p. 171).

"O ato amoroso é um ato que acolhe atos, ações, dores e alegrias como eles são; acolhe para permitir que cada coisa seja o que é neste momento.” Portanto, como afirma Luckesi, a avaliação deve ser prazerosa, assumir sua função diagnóstica, auxiliando no processo de aprendizagem, incluindo todos neste processo, sem classificação, sem julgamentos precipitados e sim uma aprendizagem baseada na busca do conhecimento (LUCKESI, 2002, p. 172).

\section{CONSIDERAÇÕES FINAIS}

Os estudos realizados neste artigo são fundamentais para pensar a prática pedagógica que visa à formação integral dos alunos.

Espera-se que os educadores reflitam sobre seus conceitos ou concepções sobre a avaliação, transformando suas práticas no processo ensino-aprendizagem. As teorias sobre avaliação devem ser estudadas pelos educadores em qualquer momento de formação, pois a

Avaliação é uma prática diária, contínua e intencional. Ou seja, o que se pretende ensinar deve ser planejado minuciosamente para que se avalie conscientemente aquilo que foi de fato ensinado.

Não há como avaliar o que os alunos não sabem ou não aprenderam. A avaliação deve permanecer durante todo o processo de ensino aprendizagem e assumir um caráter construtivo para que o professor direcione sua prática de acordo com seus objetivos. As práticas avaliativas, sobretudo na escola, não devem assumir um caráter punitivo a fim de caracterizar os estudantes de forma que os prejudiquem cognitivamente e emocionalmente.

$\mathrm{Na}$ Educação Infantil, os estudantes também são sujeitos de direitos e devem ter suas necessidades atendidas. Os educadores que lecionam nessa etapa devem ter consciência de que a avaliação impacta positivamente no desenvolvimento dos alunos. $\mathrm{O}$ educador direciona suas ações com vistas à aprendizagem emancipadora, na perspectiva de promover os saberes esperados, assegurando o que é de direito das crianças.

Em suma, não há como afirmar que um aluno não aprendeu nada, pois seria o mesmo que dizer que nada lhe foi ensinado. Sendo assim, o propósito principal da 
avaliação, além de promover a aprendizagem dos estudantes e acompanhar o desenvolvimento durante todo o processo, viabiliza a autoavaliação.

\section{REFERÊNCIAS}

BRASIL. Ministério da Educação. Base Nacional Curricular Comum. Brasília: 2a versão revista (proposta preliminar). Abril, 2016.

BRASIL. Ministério da Educação. Secretaria de Educação Básica. Indagações sobre o Currículo. Currículo e Avaliação. Fernandes, Claudia de Oliveira. Freitas, Luís Carlos de. Brasília. 2007.

I998. $\mathrm{I}^{\mathrm{a}} \mathrm{v}$.

Referencial curricular nacional para a educação infantil. Brasília: SEF,

CERVO, A. L.; BERVIAN, P. A.; SILVA, R. Metodologia científica. 6. ed. São Paulo: Pearson Prentice Hall, 2007.

DAHLBERG, G.; MOSS, P.; PENCE, A. Qualidade na educação da primeira infância: perspectivas pós-modernas. Porto Alegre: Artmed, 2003.

DEMO, Pedro. Avaliação Qualitativa. ıo. ed. Campinas-SP: Autores Associados, 2010

HAYDT, Regina Cazaux. Avaliação do processo ensino-aprendizagem. 6a Edição. São Paulo: Editora Ática, 2008.

HOFFMANN, Jussara: Avaliar para promover - As setas do caminho. Ir.ed. Porto Alegre: Editora Mediação, 2009.

Avaliação mediadora - uma prática em construção da pré-escola à universidade. Porto Alegre: Editora Mediação, 2007.

LUCKESI, Cipriano Carlos. Avaliação da aprendizagem escolar: estudos e proposições. São Paulo: Cortez 2002.

MARCHESI, Álvaro; PÉREZ, Eva María. A Compreensão do Fracasso Escolar. In: MARCHESI, Álvaro; GIL, Carlos Hernández \& Colaboradores. Fracasso Escolar: uma perspectiva multicultural. Porto Alegre: Artmed, 2004.

OLIVEIRA, Z. M. R. Educação infantil: fundamentos e métodos. São Paulo: Cortez, 2002.

VASCONCELlOS, Celso dos S. Avaliação da Aprendizagem: Práticas de Mudança por uma Práxis Transformadora. 12. ed. São Paulo:Libertad, 2013.

ZABAlA, Antoni. A Prática Educativa: Como Ensinar. Reimpressão: 2010. Porto Alegre: Artmed, 1998. 